\title{
The Modification of Surface of Barrels by Gas Nitriding
}

\author{
Zdenek Pokorny, David Dobrocky, Zdenek Joska \\ Faculty of Military Technology, University of Defence, Kounicova 156/65, 66210 Brno, Czech Republic. \\ E-mail: zdenek.pokorny@unob.cz
}

Steels which are used for manufacturing of highly stressed parts of military equipments such as barrels of small arms weapons must be modified by heat treatment due to achieve required mechanical properties. Moreover, other important properties of functional parts, especially a friction coefficient and surface parameters of bore of barrels, must be optimized due to obtain the best accuracy in target and to increase the life time of barrel $[1,2]$. The technology chromium plating, very widespread in the past, has been gradually replacing by more ecological methods. This article is devoted to find a technology as a replacement of traditional chromium plating. Experiments are focused on using of optimized gas nitriding processes for surface treatment. As a result, a higher surface hardness with low influence on the dimensional accuracy is expected. Gas nitriding process was applied to steels $42 \mathrm{CrMo} 4$ and 32CrMoV12-10 used for barrel manufacturing. The most important parts of barrel were evaluated, especially surface parameters as a morphology then chemical composition and naturaly a microstructure of the material. The analysis of surface morphology was performed by scanning electron microscopy; chemical composition was evaluated by GDOES method and mechanical properties by using microhardness methods. The measurements of depth of diffusion layer were performed by destructive and non-destructive methods. The measurements showed the influences of chemical composition of alloying elements in core of material after chemical-heat treatment process on depth of diffusion and influence of technology on development of porosity. All fundamental mechanical properties significant for requiring function of barrel were documented [1, 2]. Nevertheless, the main task was the description of the porosity development in compound layer after gas nitriding and the increasing of surface hardness and the depth of diffusion layer according to chemical composition. Nitriding process was applied for increasing of surface hardness of material in depth and improving of mechanical properties. Mechanical properties of tested material were significantly increased.

Keywords: Nitriding; Microhardness; Nitrided layer; Porosity, Non-destructive testing.

\section{Introduction}

The technology "chromium plating" has been gradually replaceing by new technologies. Unfortunatelly, it is very difficult to replace special characteristics of chromium plated layers. One of the possible technologies could be nitriding. The aim of this paper is to achieve an enhanced surface hardness and reduced friction coefficient with predictable presence of porosity. Chemical-heat treatment process supports primarily the creation of the interstitial phases of nitrides and carbides of iron. These initial phases of nitrides and carbides are primarily created in the biggest defects, at grain boundaries. Generally, iron nitrides and carbides increase the microhardness only negligibly. Generally, the fundamental elements causing increasing of fundamental mechanical properties are molybdenum, vanadium, aluminium or chromium [1].

The surface hardness after chemical-heat treatment depends on two fundamental phenomenons. Firstly on microstructure and finally on content of suitable alloying elements that are capable to create very hard phases [3]. The selection of steel is the most important at all for these chemical processes and is connected to machining $[4,5]$.

Created compound layer has been very hard, but could be very brittle, with good friction and anticorrosion properties $[6,7]$. The thickness and hardness of $\gamma^{\prime}-\mathrm{Fe}_{4} \mathrm{~N}$ (diffusion layer) depends on quantity of alloying elements and on duration of process $[6,7,8,9]$. Therefore, this paper demonstrates the influence of selected alloying elements on increasing of surface hardness, microhardness and the influence of process on surface morphology.

Chemical composition of steel was analyzed by GDOES/Bulk method on LECO SA 2000 spectrometer and local measurement of composition was carried out on SEM microscope Hitachi Tabletop 3000. Microstructure was evaluated by electron microscopy method on Hitachi Tabletop 3000. Thickness and microhardness of nitrided layers were measured by microhardness method in accordance with DIN 50190 standard on automatic microhardness tester LECO LM 247 AT $[11,12]$ and compared by non-destructive 
micromagnetic BNA method using ROLLSCAN 200D. The results of experiemnts bring new information about diffusion technology and its usability for small arms weapons. The characteristics of surface are significant in context of diffusion application what connected to machining $[13,14]$.

\section{Experimental}

Experimental part is based on two steels used for barrels manufacturing. Experiments were realized by using experiences from Czech producer of small arms weapons. Steel 42CrMo4 (A4) and 32CrMoV12-10 (B4) in untreated state were heat-treated (Tab. 1). The quenching $(\mathrm{Q})$ and tempering $(\mathrm{Q}+\mathrm{T})$ processes were performed to obtain two different microstructures with different parameters of initial microhardness and different redistribution of iron in crystal lattice. The different redistribution should have the significant influence on diffusion process. It was expected to obtain the different depths of nitride layers according to substitual elements and their affinity to N. Of course, the chemical composition has remarkable influence on diffusion process, too. The substitution elements influence the diffusion process, some of them in positive way.

Tab. 1 Temperature of heat-treated steels

\begin{tabular}{|c|c|c|}
\hline \multirow{2}{*}{ Steel } & \multicolumn{2}{|c|}{ Procedure } \\
\cline { 2 - 3 } & Quenching/20' & Tempering/30' \\
\hline 42CrMo4 & $860^{\circ} \mathrm{C}$, water & $600^{\circ} \mathrm{C}$, water \\
\hline $\begin{array}{c}32 \mathrm{CrMoV} 12- \\
10\end{array}$ & $940^{\circ} \mathrm{C}$, water & $600^{\circ} \mathrm{C}$, water \\
\hline
\end{tabular}

The chemical composition of material was evaluated by GDOES/Bulk method (Tab. 2). Glow discharge optical spectroscopy (GDOES) measurements were performed in LECO SA 2000, with argon glow discharge plasma excitation source, calibration of nitrogen: JK41-1N and NSC4A standards. Chemical composition test verified chemical composition according to standards. Chemical composition will play significant role during diffusion process.

Tab. 2 Chemical composition of steels measured by GDOES/BULK method

\begin{tabular}{|c|c|c|c|c|c|c|c|}
\hline & \multicolumn{7}{|c|}{ Concentration [wt. \%] } \\
\hline Material No. & $\mathrm{C}$ & $\mathrm{Mn}$ & $\mathrm{Si}$ & $\mathrm{Cr}$ & $\mathrm{Ni}$ & $\mathrm{Mo}$ & $\mathrm{V}$ \\
\hline 42CrMo4 & 0.38 & 0.81 & 0.35 & 1.09 & 0.06 & 0.19 & 0.02 \\
\hline \multirow{2}{*}{ 42CrMo4 standard } & 0.38 & 0.60 & \multirow{2}{*}{$<0.40$} & 0.90 & \multirow{2}{*}{$<0.30$} & 0.15 & \multirow{2}{*}{-} \\
\cline { 2 - 3 } & 0.45 & 0.90 & & 1.20 & & 0.30 & \\
\hline \multirow{2}{*}{ GDOES 32CrMoV12-10 } & 0.31 & 0.47 & 0.28 & 3.10 & 0.10 & 0.88 & 0.27 \\
\hline \multirow{2}{*}{ 32CrMoV12-10 standard } & 0.30 & \multirow{2}{*}{$<0.60$} & \multirow{2}{*}{$<0.35$} & 2.80 & & 0.80 & 0.25 \\
\cline { 2 - 2 } & 0.35 & & & 3.20 & & 1.20 & 0.35 \\
\hline
\end{tabular}

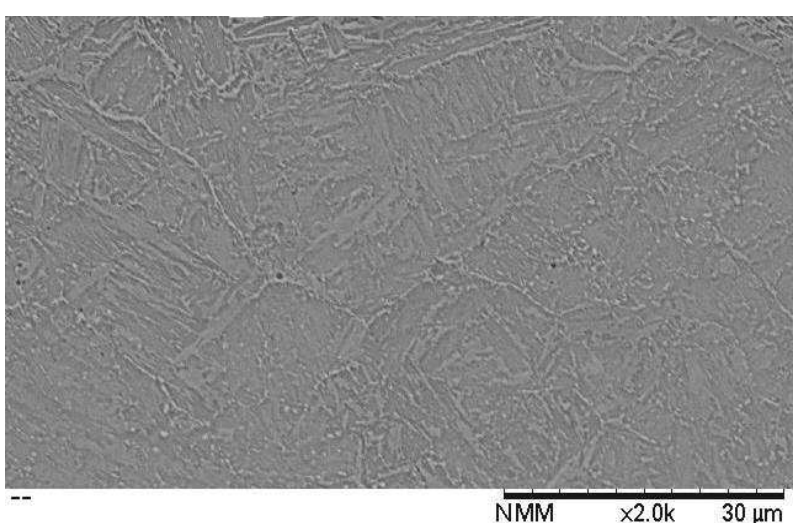

Fig. 1 The chemically etched SE cross-sectional structure of tempered steel, magnification $2000 x$

The microstructure of samples was observed by utilizing of electron microscopy method and was performed on SEM Hitachi Tabletop 3000 before and after chemical-heat treatment due to comparison of results. The structure after hardening is displayed in Fig.
1. The conditions of heat-treatment process are given in Tab. 1. Gas nitriding process was performed in NITREX appliance for 8 hours in two step process at $530^{\circ} \mathrm{C}$.

The microstructure and the surface morphology were evaluated by SEM method on electron microscope Hitachi Tabletop 3000 and the result of microstructure after quenching is given in Fig. 1. The documentation of surface morphology is given in Fig. 2 in coparison with plasma nitriding surface.

The evaluation of depth of diffusion layer was measured by microhardness method from the core of steel to the surface of the layer after nitriding by Vickers microhardness destructive method on the automatic microhardness tester LM 247 AT LECO equipped by AMH55 software under loading of 0.05 kgf for $10 \mathrm{~s}$ dwell time (Tab. 3). The depth was nondestructive checked by micromagnetic BNA method using ROLLSCAN 200D (Fig. 3). Non-destructive method is only comparable method nevertheless it has significant value. 
Tab. 3 Depth of created layer after nitriding process process

\begin{tabular}{|c|c|c|c|c|}
\hline \multirow{2}{*}{ Technology } & \multicolumn{3}{|c|}{ Depth $(\mu \mathrm{m})$} \\
\cline { 2 - 5 } & \multicolumn{2}{|c|}{ 42CrMo4 } & \multicolumn{2}{c|}{ 32CrMoV12-10 } \\
\cline { 2 - 5 } & Compound layer & Diffusion layer & Compound layer & Diffusion layer \\
\hline Nitriding & 8.70 & 0.21 & 8.60 & 0.22 \\
\hline
\end{tabular}
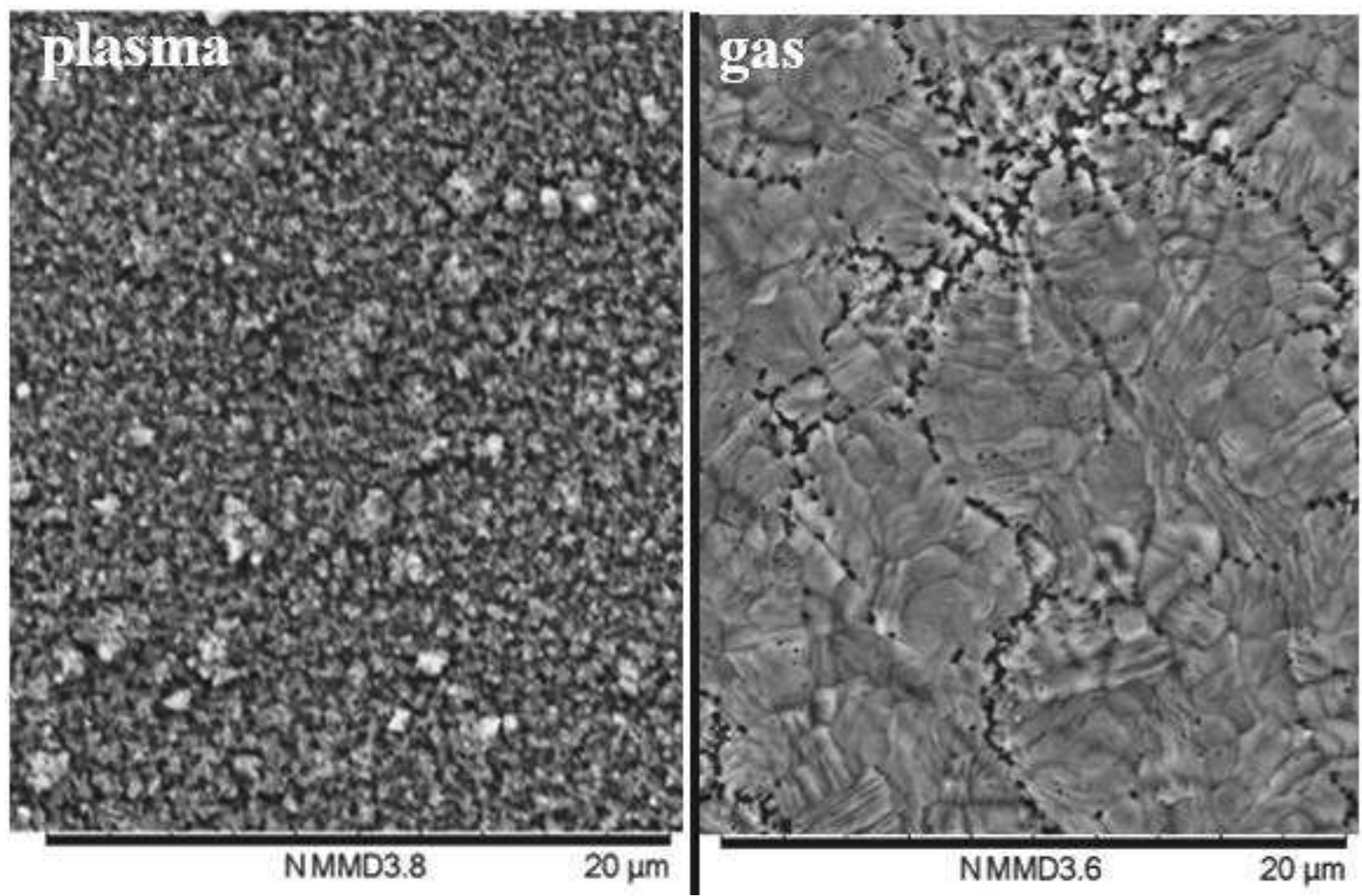

Fig. 2 Surface morphology of steel 32CrMoV12-10 after plasma and gas nitriding

These selected steels have defined differences in chemical composition (see Tab. 2). The main task was to verify the influence of chemical composition on layer characteristics. It was expected that higher content of chromium, molybdenum and vanadium caused increase of depth of diffusion layer and help to obtain higher level of stable surface microhardness.

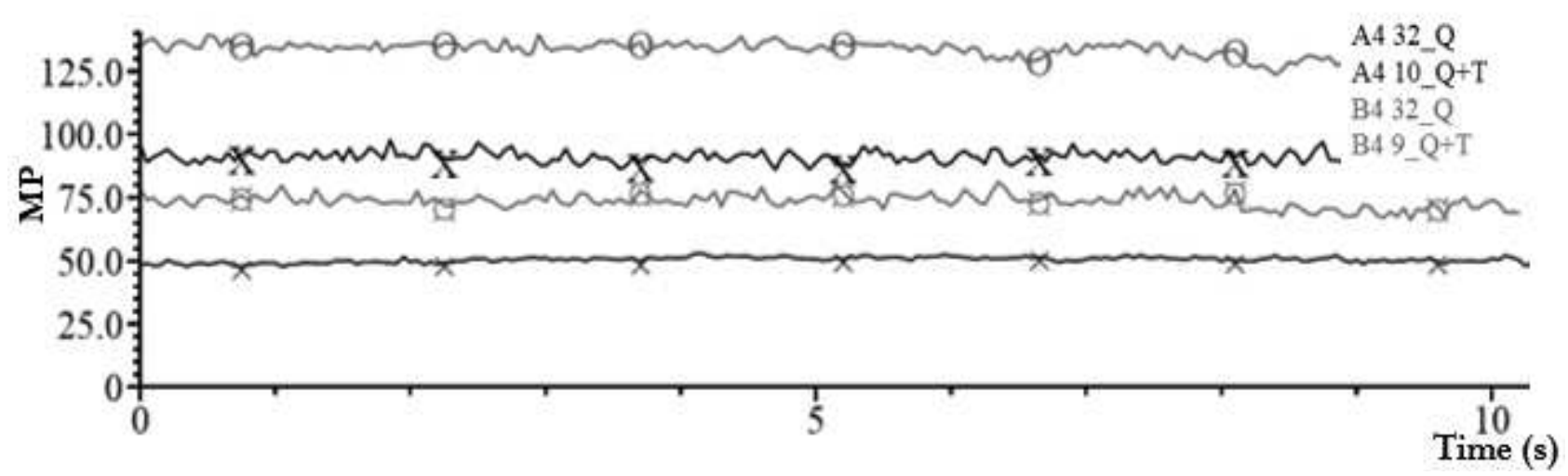

Fig. 3 BN response on 42CrMo4 and 32CrMoV12-10 samples with different HT

After preparation and nital etching, the electron microscope Hitachi Tabletop 3000 was used for observation of thickness of compound layer and especially the documentation of porosity present in the top of compound layer. The thickness and porosity were measured by using SE method and magnification 5000x (Fig. 4). 


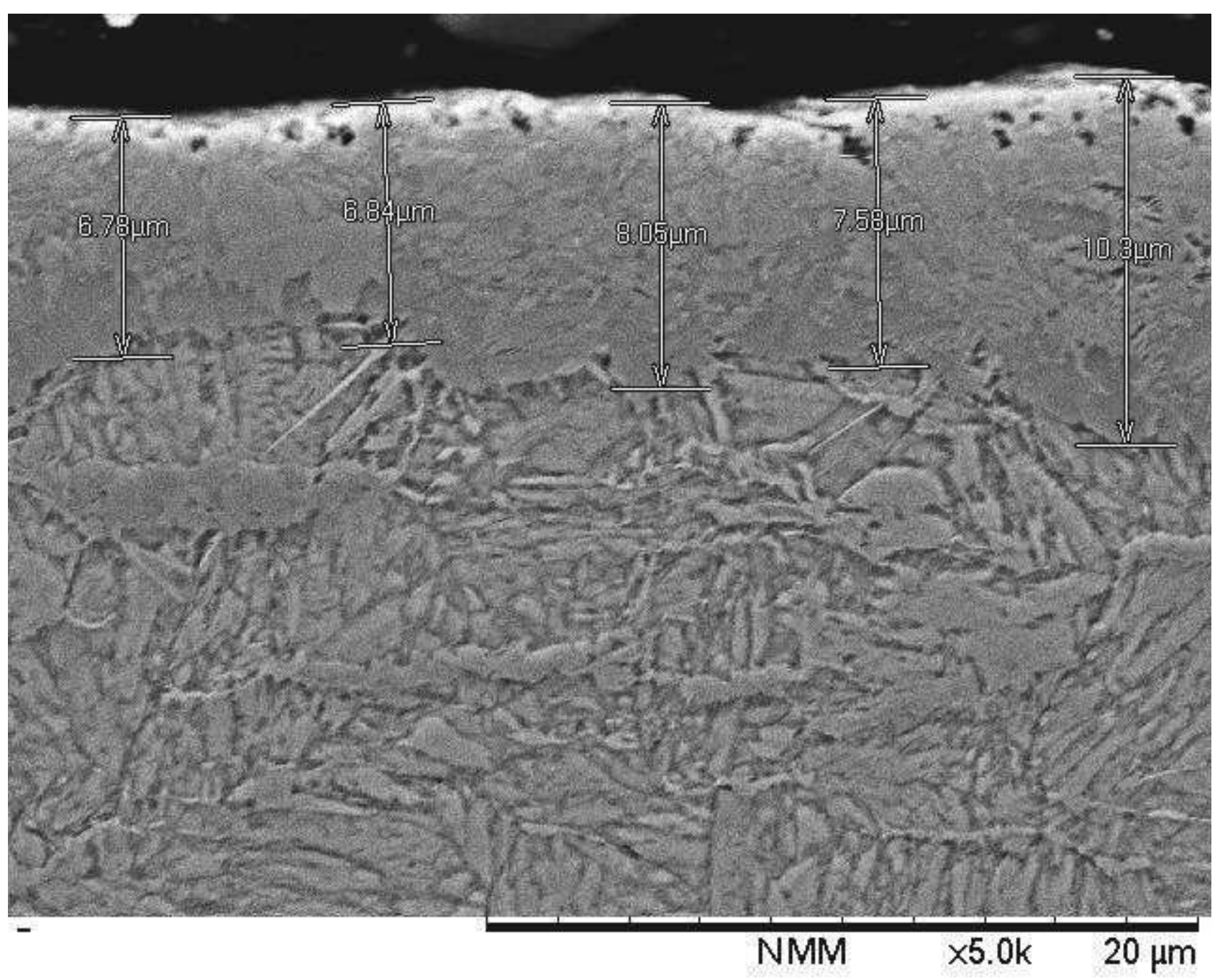

Fig. 4 The chemically etched SE cross-sectional structure of tempered steel 32CrMoV12-10 after nitriding process, compound layer with porosity (top of surface) and diffusion layer below, magnification $5000 x$

\section{Results and discussion}

Two steels 42CrMo4 and 32CrMoV12-10 were experimentally tested. The microstructure was evaluated by SEM method on microscope Hitachi Tabletop 3000. The structure was developed by nital etching and was estimated as martensitic microstructure with marks of bainite (see Fig. 1). The differencies in microstructure in both steels after quenching and tempering was noticeable in graininess of the structure and is not a supporting part of this experiment. The chemical composition of steel was checked by GDOES method on SA 2000 Leco surface analyzer. The measurements showed the specific chemical composition of selected steels, especially chromium, molybdenum and vanadium concentration (Tab. 2). The concentration of molybdenum and chromium influences the fundamental mechanical properties, especially surface microhardness after chemical-heat treatment processes (compare Tab. 2, Fig. 5). The experiments proved the importance of alloying elements concentration as $\mathrm{Cr}$ and $\mathrm{Mo}$, and their influence on the case depth development. Moreover, the presence of these alloying elements caused the increasing of surface microhardness after chemical-heat treatment (Fig. 5).

It was proved that in case of steel $32 \mathrm{CrMoV} 12-10$, the surface hardness and the depth of diffusion layer after the chemical-heat treatment is steeper than in case of sample $42 \mathrm{CrMo} 4$. It was caused due to higher concentration of chromium, molybdenum and vanadium. The concentration of alloying elements mangannese, silicon and interstitial element carbon is similar (see Tab. 2). Thanks to the same conditions of nitriding process there was possible to evaluate the influence of substitution elements on creation of surface hardness of diffusion layer and depth of nitriding (thickness of diffusion layer).

The depth of diffusion layer was increased by higher concentration of chromium and molybdenum (Fig. 5). By increasing of Ni concentration the hardness was decreased [1]. 


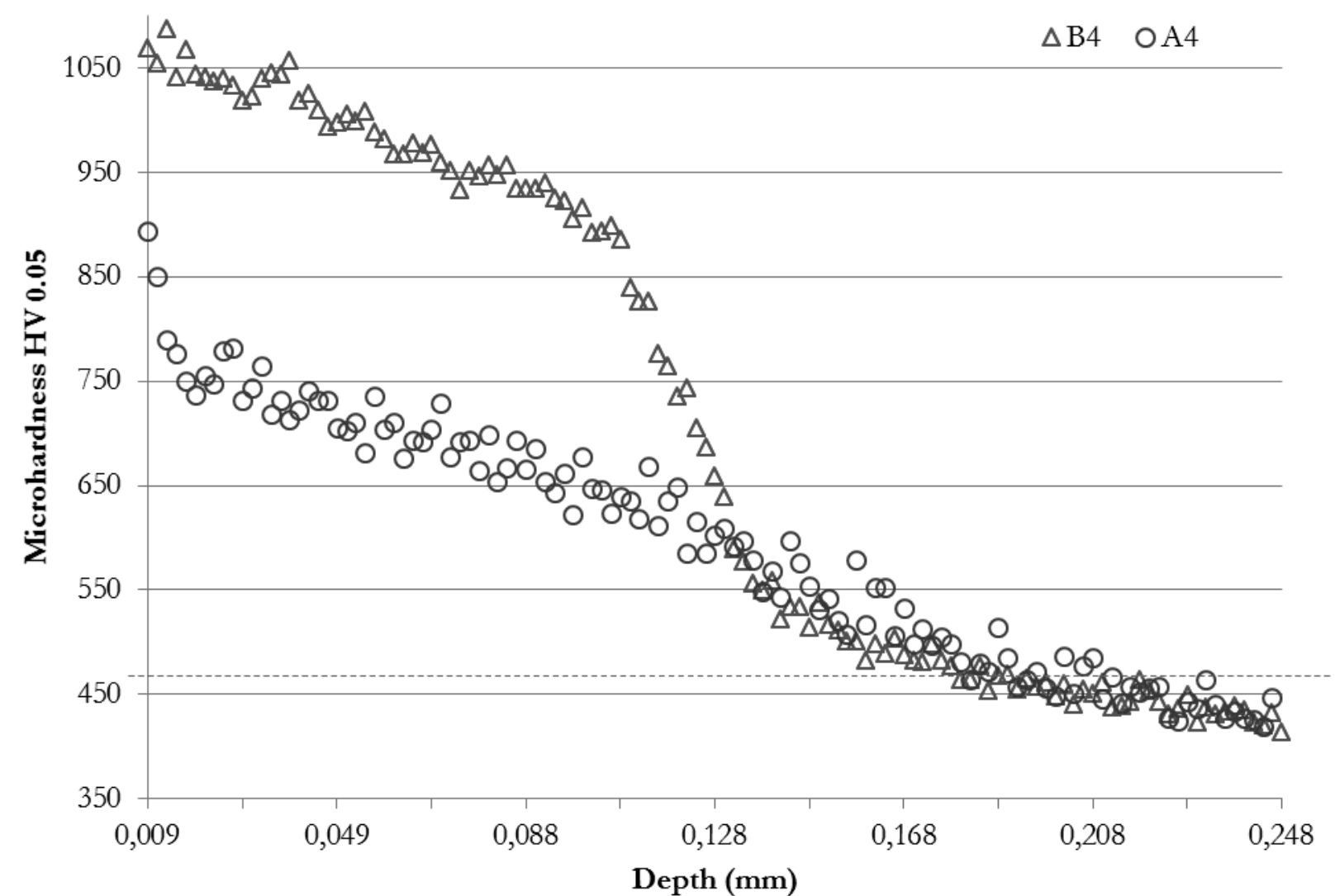

Fig. 5 Influence of alloying elements on surface hardness and depth of nitriding

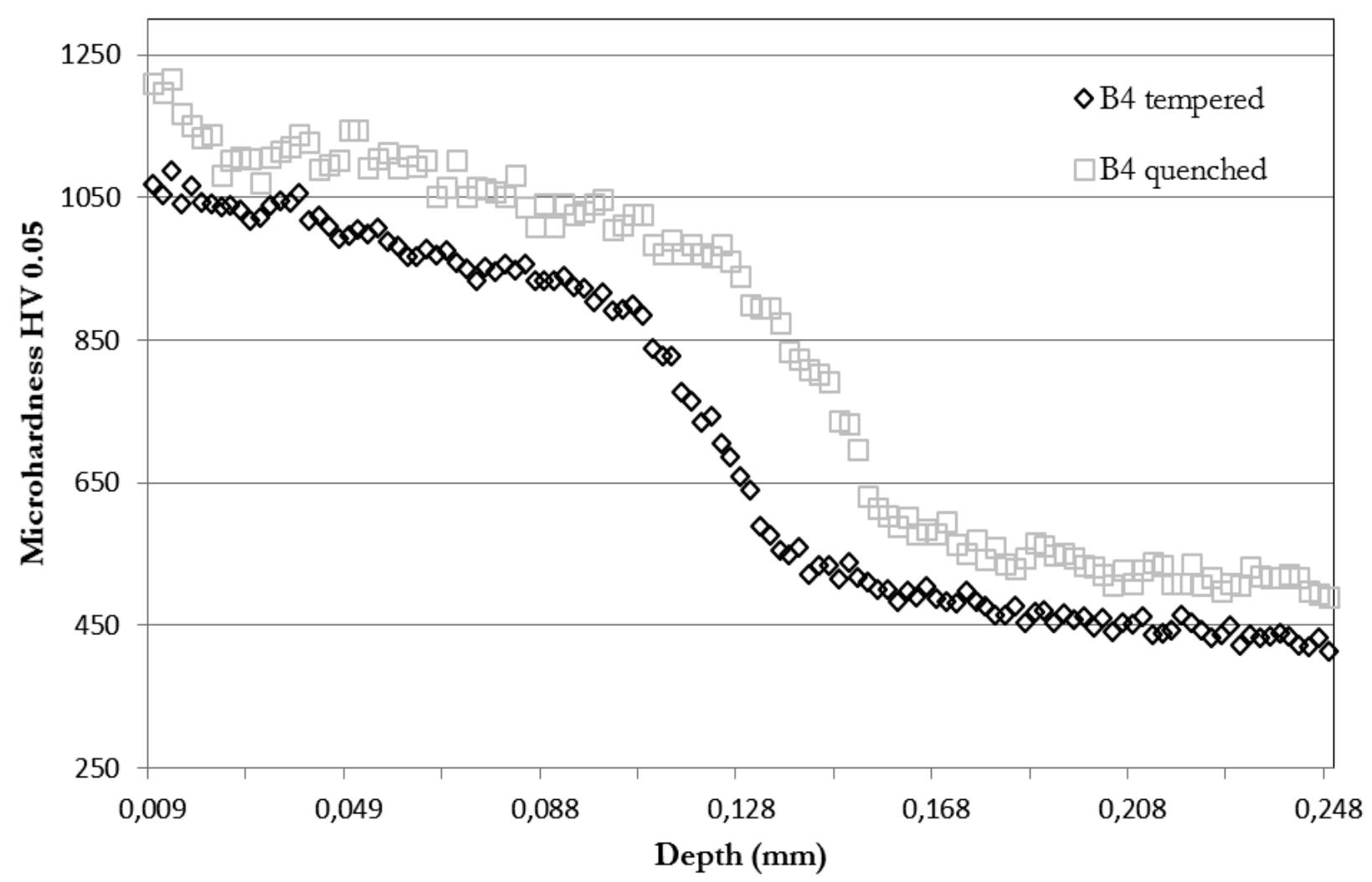

Fig. 6 Differencies of microhardness depth profiles of 32CrMoV12-10 caused by differences initial microstructure 
Moreover, the experiments proved that the increasing of surface microhardness after gas nitriding process is depended on initial microhardness. This phenomenon was found out thanks to differences in microstructure after heat treatment process, especially due to initial surface hardness before nitriding (compare Fig. 6). The initial surface microhardness of steel after quenching is usually decreased after process of chemical-heat treatment than in case of tempering (see Fig. 6). The values of surface microhardness of diffusion layer were evaluated by microhardness method and they were measured as a higher in case of quenched samples (Fig. 6). The surface status of nitride samples with different HT was checked by micromagnetic method using Rollscan 200D (fig.3). Samples of both materials after tempering show lower $\mathrm{BN}$ signal than on parts before tempering although hardnesses are lower as shown on Fig 5 and 6. The reason should be in different thicknesses of surface layer. In this case after some additional tests BNA can be used for fast and non-destructive thickness determination of surface layer.

The thicknesses of compound layer measured by SEM method of all samples are given in Tab. 3. The porosity of compound layer after gas nitriding was evaluated by using electron microscopy (Fig. 7). The presence of pores after plasma nitriding is negligible [1].

The influence of chemical composition on the sizes of pores was not confirmed. Porosity was present only in the top part of compound layer. The pores are created just only in new established part of compound layer.

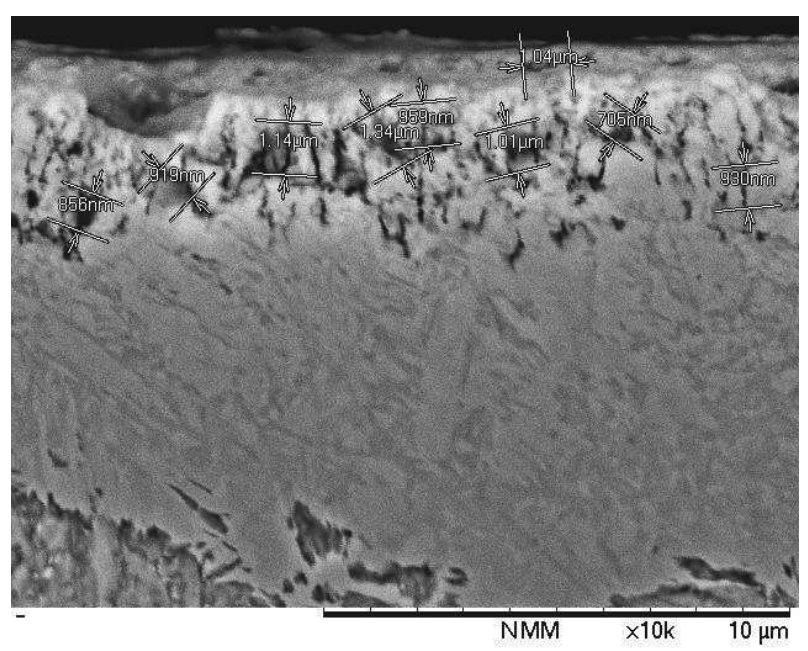

Fig. 7 The chemically etched SE cross-sectional structure of tempered steel $A 4$ after gas nitriding, documentation of porosity, magnification $10000 x$

\section{Conclusions}

These evaluated steels in two different states and different chemical composition were used for experiments concerning the porosity, microhardness and thickness and hardness of nitride layer. The concentration of alloying elements molybdenum and chromium caused the increasing of surface microhardness and it was proved that these elements have remarkable influence on microhardness trend and depth of diffusion layer. The influence of these elements to the thickness of compound layer was not confirmed. The most occurrences of pores were estimated in the top part of compound layers in all tested steels after gas nitriding.

The experiments proved that the conditions of the nitriding process influenced surface parameters of new created surface layer. The fundamental differencies in surfaces are connected with surface hardness and surface morphology. The differencies in curves (pores), their sizes, depth and stability relates with surface topology. The surface topology playes the most significant role inside cavities or barrels. The heterogeneities in surface cause the nucleation of cracks and negatively influence the life-time of barrels during shooting. The mechanism of degradation of inner part of weapon is connected with high preasure, temperature and high velocity and the degradation is mostly extremely fast, sometimes few shots. The wear is manifested by inaccuracy of shooting.

The main area of occurrence of pores was established in part of new grown part of compound layer. We are able to reliably define this porosity layer as a new established layer having strict influence on dimensional accuracy. The significant result is a claim that the chemical composition of steel has no influence on occurrence of porosity but the biggest influence on depth was caused by initial microhardness (see Fig. 6).

Important resuts is that the initial mictostructure has significant influence on diffusion process. On the base of results it seems to be more effective to nitride machine parts after quenching. The magnetic method confirmed the capability to replace destructive method for verification of quality inner small cavities.

\section{Acknowledgement}

The present research work was supported by the project The Development of Technologies, Design of Firearms, Ammunition, Instrumentation, Engineering of Materials and Military Infrastructure "VÝZBROJ (DZRO K201)" and "Surface technology in applications special techniques SV19-216".

\section{References}

[1] POKORNY, Z., DOBROCKY, D., KADLEC, J. (2018). Influence of alloying elements on gas nitriding process of high-stressed machine parts of weapons. In: Metallic materials, vol. 56 , issue 2 , p. $97-103$ 
[2] POKORNY, Z., BARBORAK, O., HRUBY, V. (2012) Characteristics of plasma nitrided layers in deep holes. In: Metallic materials, vol. 50, issue 3, p. 209-212.

[3] POKORNY, Z., STUDENY, Z., POSPICHAL, M., JOSKA, Z., HRUBY, V. (2015). Characteristics of plasma nitrided layers, In: Manufacturing Technology, Vol. 15, No. 3, Pages 403-409.

[4] SEDLÁK, J., DRÁBEK, T., MOURALOVÁ, K., CHLADIL, J., KOUŘIL, K. (2015) Machining Issues of Titanium Alloys. In: International Journal of Metalcasting, Vol. 9, No. 2, p. 41-50.

[5] MAJERNÍK J., PODAŘIL, M. (2019). Evaluation of the temperature distribution of a die casting mold of X38CrMoV5_1 steel, In: $A r$ chives of Foundry Engineering, vol. 19, pp. 107-112.

[6] HUTSAYLYUK, V., ŚNIEŻEK, L., SULYM, H., PASTERNAK, I.A., TURCHYN, I. (2014). Transient Dynamic Stress-strain State and Thermomechanical Transformation of a Rectangular Plate under High-speed Deformation, In: Procedia Materials Science, Vol. 3, pp. 2092-2097.

[7] CHAUSOV, M., HUTSAYLYUK, V., SNIEZEK, L., MARUSCHAK, P., PYLYPENKO, A. (2016). Complete StressStrain Curve as a Source of Information on the Kinetics of Fracture of Titanium Alloys Subjected to a Combined Mode of Loading, In: 5 th International Conference Integrity - Reliability Failure IRF16, Porto, Portugal, pp. 109-116.

[8] KOSTUREK, R., NAJWER, M., NIESLONY, P., WACHOWSKI, M. (2018). Effect of Heat Treatment on Mechanical Properties of Inconel 625/Steel P355NH Bimetal Clad Plate Manufactured by Explosive Welding. In: Advances in Manufacturing, pp 681-686.
[9] MAJERÍK, J., DUBOVSKÁ, R., JAMBOR, J., ČEP, R., KRATOCHVÍL, J., KOUŘIL, K. (2018). Experimental investigation into wear and tool life of milling cutter PVD coated carbide inserts while armox 500 steel hard milling. In: Tehnickei Vjesnik, Vol. 25, Issue 6, p. 16031610.

[10] KUSMIERCZAK, S., NAPRSTKOVA, N. (2018). Analysis of Al-Si layer on steel sheet during thermo mechanical processing using microscopic methods. In: Manufacturing Technology, Vol.18, No 5, pp. 769-774.

[11] ČSN ISO 14577-1 METALIC MATERIALS Instrumected indentation test for hardness and materials parameters - Part 1: Test method.

[12] DIN 50190-4:1999, Hardness depth of heattreated parts - Part 4: Determination of the diffusion hardening depth and the diffusion depth.

[13] HUTSAYLYUK, V., SNIEZEK, L., CHAUSOV, M., TORZEWSKI, J., PYLYPENKO, A., WACHOWSKI, M. (2016). Cyclic deformation of aluminium alloys after the preliminary combined loading. In: Engineering Failure Analysis, Vol. 69, pp. 66-67.

[14] SEDLAK, J., MALASEK, J., ONDRA, M., POLZER, A. (2016). Development and production of prototype model of axial fan, In: $\mathrm{Ma}$ nufacturing Technology, 16 (2), pp. 436-444.

[15] DUBOVSKA, R., MAJERIK, J., ČEP, R., KOUŘIL, K. (2016). Investigating the influence of cutting speed on the tool life of a cutting insert while cutting DIN 1.4301 steel. In: Materiali in Tehnologije, Vol. 50, No. 3, p. 439445. 